\title{
Latent Structure of Antisocial and Borderline Personality Disorders: A Taxometric Research ${ }^{1}$
}

\author{
Lucas de Francisco Carvalho ${ }^{2}$, Nelson Hauck Filho², Giselle Pianowski², Luana Comito Muner ${ }^{3}$ \\ ${ }^{2}$ Universidade São Francisco, Campinas-SP, Brazil \\ ${ }^{3}$ Faculdade Cathedral, Boa Vista-RR, Brazil
}

\begin{abstract}
Establishing personality disorders as categorical or continuous entities is still an ongoing issue, under examination in both psychiatry and psychology. Regarding antisocial (APD) and borderline (BPD) personality disorders, taxonomic analysis have revealed controversial and, therefore, inconclusive results. This study sought to employ taxometric methods in the investigation of the latent structure of APD and BPD. Taxonomically, indicators related to the APD and BPD of the Dimensional Clinical Personality Inventory (IDCP) were analyzed in a clinical sample $(N=282 ; 63.5 \%$ women, mean age $=38.38, S D=13.59)$ and a community sample $(N=7,091 ; 78.8 \%$ women; mean age $=22.20, S D=8.51)$. Mean CCFI was 0.276 for APD and 0.401 for BPD. Findings apparently refute the traditional categorical nosography as a viable modeling approach for the latent structure of both disorders, besides clearly suggesting a dimensional structure for APD.
\end{abstract}

Keywords: psychiatry, personality disorders, diagnosis, psychometrics

\section{A Estrutura Latente dos Transtornos de Personalidade Antissocial e Borderline: Uma Investigação Taxométrica}

Resumo: A identificação dos transtornos da personalidade como entidades categóricas ou contínuas ainda está sob investigação na psiquiatria e psicologia. No que diz respeito aos transtornos de personalidade antissocial (TPA) e borderline (TPB), análises taxométricas têm revelado resultados controversos, logo, inconclusivos. Partindo disso, este estudo buscou empregar métodos taxométricos na investigação da estrutura latente dos TPA e BPD. Foram analisados taxometricamente indicadores relacionados aos TPA e BPD do Inventário Dimensional Clínico da Personalidade (IDCP) em uma amostra clínica $(N=282 ; 63,5 \%$ mulheres; idade média $=38,38$, com $D P=13,59)$ e outra da população geral $(N=7.091 ; 78,8 \%$ mulheres; Idade média $=22,20$, com $D P=8,51)$. Os índices CCFI médios foram 0,276 para TPA e 0,401 para BPD. Os achados parecem refutar a perspectiva nosográfica categórica tradicional enquanto uma adequada perspectiva de modelagem latente de ambos os transtornos, além disso, sugerindo, claramente, uma estrutura dimensional para o TPA.

Palavras-chave: psiquiatria, transtornos da personalidade, diagnóstico, psicometria

\section{Estructura Latente de los Trastornos de Personalidad Antisocial y Borderline: Una Investigación Taxométricos}

\begin{abstract}
Resumen: La identificación de los trastornos de personalidad como algo categórico o continuo aún está en discusión en la psiquiatría y la psicología. En lo referente a los trastornos de personalidad antisocial (TPA) y borderline (BPD), análisis taxométricos han mostrado resultados contradictorios, y por lo tanto, inconclusos. A partir de eso, este estudio buscó utilizar métodos taxométricos para investigar la estructura latente del TPA y del BPD. Fueron analizados los datos de indicadores relacionados a los TPA y BPD del Inventario Dimensional Clínico de la Personalidad (IDCP) en una muestra clínica $(N=282 ; 63,5 \%$ mujeres; edad promedio $=38,38$, con $D T=13,59)$ y una muestra de población general $(N=7.091 ; 78,8 \%$ mujeres; edad promedio $=22,20$, con $D T=8,51)$. El índice CCFI medio resultó en 0,276 para el TPA y en 0,401 para el BPD. Los hallazgos parecen rechazar la nosografía categórica tradicional en lo referente a una perspectiva adecuada de modelaje de la estructura latente de ambos trastornos, sugiriendo principalmente una estructura categórica para el TPA.
\end{abstract}

Palabras clave: psiquiatría, trastornos de la personalidad, diagnóstico, psicometría

\footnotetext{
${ }^{1}$ Paper derived from the doctoral dissertation by the first author, under the advice of the second author and co-advice of the third author, defended in the Graduate Program in Psychology at the Universidade de São Paulo. Support: São Paulo Research Foundation (FAPESP, Grant \# nº 2012/12794-9).

Correspondence address: Lucas de Francisco Carvalho. Universidade São Francisco. Departamento de Psicologia. R. Waldemar César da Silveira, 105, Jardim Cura D'Ars (SWIFT), Campinas-SP, Brazil. CEP 13.045-510. E-mail: lucas@labape.com.br
}

An essential question about the nature of mental disorders is to determine whether they are categorical or continuous entities. In other words, it is to know which of these disorders designate qualitatively distinct types (that is, categories, latent classes, clusters or tax) of individuals, and which of them, instead, refer to a continuum (that is, dimension, factor or trait) over which individuals vary 
quantitatively (Meehl, 1992, 1995). Although personality disorders (PDs) appear in nosography manuals as categorical entities, they have led to theoretical and literature synthesis investigations that are more coherent with a dimensional model (Samuel \& Widiger, 2008; Trull, 2005; Trull \& Durrett, 2005; Trull, Tragesser, Solhan, \& SchwartzMette, 2007). The tension between the categorical and the dimensional approaches of PDs can be exemplified by the inclusion, in Section III of the fifth edition of the Diagnostic and Statistical Manual of Mental Disorders - DSM-5 (American Psychiatric Association [APA], 2013), of a hybrid model for the assessment of PDs that keeps characteristics of both perspectives. This paper aims to contribute to the debate about the nature of PDs investigating specifically the latent structure of the Antisocial (APD) and Borderline (BPD) personality disorders based on the taxometric method.

PDs cause significant damage to diagnosed individuals and are considered a pattern of functioning persistently deviant from cultural expectations related to both observable behaviors and internal experiences (APA, 2013). The potential impact on society is indicated by the prevalence of $9.1 \%$ of PDs in the population (APA, 2013, Peluso \& Andrade, 2011). Among the most studied PDs are APD and BPD (Charlize, 2014; Sprague, Javdani, Sadeh, Newman, \& Verona, 2012; Walters, 2008, 2015), with prevalence rates of $0.2 \%$ to $3.3 \%$ for APD - most commonly in men, and from $1.6 \%$ to $5.9 \%$ for BPD - predominantly in women (APA, 2013). The clinical relevance of these two PDs is highlighted by the difficult management they impose (Pinto, 2006; Romaro, 2002; Sadi, 2011; Sousa, 2003; Tanesi, Yazigi, Fiore, \& Pitta, 2007; Zanin \& Valerio, 2004).

As part of DSM-5 Section II Cluster B for PDs, APD and BPD are explained and diagnosed based on the categorical model. That is, they are qualitatively distinct and identified by means of diagnostic criteria (APA, 2013). In this section, APD is understood as a pattern of social maladjustment manifested by disrespect and violation of the rights of others, arranged in four sets of diagnostic criteria (A, B, C, and D). Criterion A comprises seven distinct manifestations, including disrespect to norms, deceitfulness, impulsivity, irritability and aggressiveness, disrespect for safety of self or others, irresponsibility and lack of remorse. For its identification, the individual must present at least three of the seven manifestations: (A), being at least age 18 (B), evidence of conduct disorder before age 15 (C) not occurring concomitantly to the course of schizophrenia or bipolar disorder (D) (APA, 2013). BPD, in turn, consists of a pattern of instability of interpersonal relations, self-image, and affects, as well as marked impulsivity, arranged in nine diagnostic criteria. For its identification, the individual must present five or more criteria, which include avoidance of abandonment, relational and affective instability, identity disturbance, impulsivity, self-mutilation and suicidal behavior, difficulty in controlling anger, and paranoid ideation and/or dissociative symptoms (APA, 2013).

The literature has shown that despite the differences between the genders, APD and BPD are two highly comorbid disorders (Paris, 1997), sharing neurobiological bases (Völlm et al., 2004) and etiological aspects (Beauchaine, Klein, Crowell, Derbidge, \& Gatzke-Kopp, 2009). In particular, impulsivity seems to be a common point in both disorders (APA, 2013). In fact, there is evidence that both APD and BPD are based on a high sensitivity of the Behavioral Approach System (BAS), which represents the set of brain structures responsible for the activation of emotional, motivational and behavioral aspects in the face of stimuli that sign rewards (Ross, Keizer, Strong, \& Webb, 2013). In the case of APD, it is possible that the resulting impulsivity is more generalized to several contexts, whereas in BPD it may occur in the form of active avoidance behaviors in the face of urgency and emotional stress (it may even manifest as self-harm). In addition, both disorders are positively associated with a psychopathic personality dimension known as "Factor 2" or "secondary", which is centered precisely on reduced selfcontrol and impulsivity (Huchzermeier et al., 2007). In the case of BPD, this connection with psychopathy appears to be even greater among women (Sprague et al., 2012). In view of the possible shared psychological mechanisms, both disorders are object of investigation in the present study, in order to establish if, in fact, they have the same latent structure - categorical or dimensional.

In contrast to the categorical model, in the hybrid model (APA, 2013), PDs are understood as profiles formed from personality traits at pathological levels, impairing the functioning of the individual. In this case, it is understood that each individual presents all the traits at some level (Krueger, Derringer, Markon, Watson, \& Skodol, 2012; Shedler et al., 2010; Trull, 2007; Zimmerman, 2012), which is different from considering that qualitative differences exist only between one group with and another without a given PD. The alternative dimensional diagnosis of PD occurs by evaluating the severity of personality functioning impairment (criterion A), identification of pathological traits (criterion B), among 29 facets distributed in five dimensions, stability and inflexibility of the manifestations (criteria $\mathrm{C}$ and $\mathrm{D}$ ), and differential diagnoses (criteria E, F and G). Particularly regarding the APD, stand out the traits of manipulation, detachment, deceitfulness, hostility, risk taking, impulsivity and irresponsibility. In relation to the BPD profile, the traits that stand out are emotional lability, anxiousness, separation insecurity, depression, impulsivity, risk taking and hostility.

Studies have empirically investigated the nature of the latent structure of APD and BPD, seeking to resolve the controversy of the categorical and dimensional approaches of these disorders. The results do not seem to support the categorical perspective previously used in the psychiatric diagnostic manuals, revealing the APD and BPD as having a dimensional nature (Arntz et al., 2009; Kerridge, Saha, \& Hasin, 2014; Marcus, Lilienfeld, Edens, \& Poythress, Walters, Diamond, Magaletta, Geyer, \& Duncan, 2007). In contrast, there are a number of studies pointing them as categorical in nature (Hallquist \& Pilkonis, 2012; Haslam, 2003; Lönnqvist, Verkasalo, Wichardt, \& Walkowitz, Trull, Widiger, \& Guthrie, 1990; Vasey, Kotov, Frick, \& Loney, 2005). 
Therefore, there is still an inconsistency in the results of the studies that addressed the latent structure of APD and BPD, the two most studied PDs in the literature. While factorial studies support a dimensional perspective of the disorders, studies based on cluster analysis and various methods point to a categorical structure composed of qualitatively distinct groups of individuals. In view of this debate in the literature, the present study intends to contribute to this discussion, seeking to use taxometric methods to investigate the nature of the latent structure of APD and BPD. Establishing whether these disorders are of a dimensional or categorical nature is fundamental both from a theoretical point of view and from professional practice, since clinicians rely on this information to support their decisions in terms of evaluation and intervention or referral.

\section{Method}

\section{Participants}

Participants of the present study are from two population groups, including 7.091adults from the Brazilian general population (mean age $=22.20$ years; standarddeviation $=8.51$ years; $78.8 \%$ women) and 282 psychiatric patients from a public hospital in the state of São Paulo (mean age $=38.38 ;$ standard-deviation $=13.59 ; 63.5 \%$ women).The first sample, called "non-clinical group", was composed mainly of university students $(90.8 \%)$, while the second, "clinical group", was composed mainly of people with a complete secondary education $(37.8 \%)$ or complete/ incomplete elementary education $(34.6 \%)$, followed by $25.6 \%$ university students and $2 \%$ graduate students. The analyzed data totaled 7.373 adults (mean age $=23.83$, standard-deviation $=10.37$ ) who responded to the research instruments.

The combined use of data of participants from the general population and of clinical patients is justified by the very nature of taxometric analysis. Specifically, investigating whether a psychological condition has a taxometric or dimensional nature depends on the availability of a database that contains at least some cases with the pathological condition in question (Meehl, 1995). There is evidence that taxometric methods present reliable results when there are as from $5 \%$ of cases with the hypothetical taxometric phenotype in the database (Ruscio \& Marcus, 2007; Ruscio et al., 2010). Thus, considering the low prevalence of both disorders in the general population, it was considered appropriate to add a clinical sample to the database, in order to increase the reliability of taxometric analysis results.

\section{Instruments}

The Dimensional Clinical Personality Inventory IDCP (Carvalho \& Primi, 2015) is a self-report test for the evaluation of pathological personality traits, and high scores are suggestive of more pathological functioning. The 163-item version was used, evaluated on a 4-point Likert scale, with 1 referring to "nothing to do with me" and 4, "everything to do with me". The mean time of application was 25 minutes. The IDCP consists of 12 dimensions: Dependency, Aggressiveness, Mood Instability, Eccentricity, Attention Seeking, Distrust, Grandiosity, Isolation, Avoidance of Criticism, Self-sacrifice, Conscientiousness, and Impulsiveness. Studies demonstrate the psychometric adequacy of its dimensions (Carvalho \& Primi, 2015, 2016; Carvalho, Primi, \& Stone, 2014). Specifically, these studies presented reliability indices in general higher than 0.70 ; evidence of validity based on the internal structure (by Classical Theory of Tests and by Item Response Theory), and based on the relationship with other variables (for example, NEO-PI-R and groups of psychiatric patients).

For the taxometric analysis, the IDCP indicators were used to evaluate APD and BPD based on the proximity between the characteristics that make up the diagnostic criteria presented in the DSM-5 (APA, 2013) and the content covered in the dimensions of the Inventory. For the evaluation of APD, the dimensions Aggressiveness, Grandiosity and Impulsiveness were included, covering contents of interpersonal hostility and reduced consideration/empathy for others, superiority, inconsequence and deceitfulness. For BPD, the dimensions Dependency, Mood Instability and Impulsiveness were considered, which include characteristics related to separation insecurity, emotional oscillation and vulnerability, as well as impulsive and extreme reactions.

\section{Procedure}

Data collection. The data were collected over the Internet and also in a public psychiatric hospital in the city of São Paulo. In the case of the Internet application, the Google Forms tool was used, generating a link in which the Informed Consent Form was made available and, in case of agreement, the participant was directed to respond the IDCP and the demographic data. At the hospital, participants were invited in a waiting room context and, if accepted, they signed the Informed Consent Form, then they filled in the IDCP and the demographic data, collectively and in paper and pen, with approximately five patients by administration, with an average time of 30 minutes. The literature suggests that, in general, pencil and paper and computerized versions are equivalent in cases of personality tests (Meade, Michels, \& Lautenschlager, 2007), which also occurs in other areas (Noyes \& Garland, 2008). Details have also been discussed in the literature regarding the application of psychological tests by the Internet (Naglieri et al., 2004).

Data analysis. Modern taxometric methods use a comparison of sample data with simulated bootstrap data, a procedure developed by Ruscio, Ruscio and Meron (2007). The technique consists of simulating data for the two conditions in which the underlying true model is taxonomic or dimensional, to identify to which of the two possibilities the data are more similar. Importantly, the data are simulated in order to maintain the descriptive characteristics of 
the researcher's empirical data. The comparison is made by analyzing root mean square residuals (RMSR) of the empirical curve when adjusted to the simulated curves (taxonic and dimensional) using the Comparison Curve Fit Index - CCFI (Ruscio et al., 2007). This index consists in FitRMSR-Dim/ (FitRMSR-Dim + FitRMSR-Tax), that is, the dimensional curve fit (in fact, residues) divided by the dimensional curve fit when added to the taxonic curve fit. All these procedures are easily implemented with just one command line when using the program developed by John Ruscio (Source Code available at https://ruscio.pages.tenj. edu/files/2016/03/Programs.zip), run by program R.

The analytical strategy employed in the present study followed the principles of consistency testing, recommended in the taxometric literature (Meehl, 1992, 1995; Ruscio et al., 2010). Consistency testing is based on the evaluation of the latent structure of the psychological attribute based on the use of different mathematically non-redundant taxometric methods. The methods used were Mean Above Minus Below A Cut - MAMBAC (Meehl \& Yonce, 1994), Maximum Eigenvalue - MAXEIG (Meehl \& Yonce, 1996), and Latent mode factor analysis - Lmode (Waller \& Meehl, 1998). The three methods have the objective to establish if the sample data come from a population in which the psychological attribute is categorical or dimensional. Readers interested in learning more about the fundamentals of these techniques can refer to the introductory work by Walters (2012).

Initially, Ruscio et al. (2007) recommended the interpretation of the CCFI index as revealing evidence of dimensionality when $0<\mathrm{CCFI}<0.50$, and suggesting taxonic (categorical structure, "types") when $0.50<$ CCFI $<1$. However, a simulated data study (Table 1) revealed that results obtained in this study are in agreement with the results obtained by Ruscio et al. (2010). Results between 0.40 and 0.60 should be interpreted as ambiguous, not allowing conclusions about the nature of the latent attribute. Another recommendation based on the simulation study by Ruscio et al. (2010) is to interpret the results only from the mean of the CCFI considering the different methods, instead of the index obtained in each method alone. These guidelines of interpretation have been adopted in the forensic and psychiatric literature (Walters, 2012), and are also employed in the present study.

\section{Ethical Considerations}

The present study was submitted to a Research Ethics Committee, receiving approval under the CAAE n. 21992113.1.0000.5514. All participants signed a free and informed consent form for participation.

\section{Results}

Table 1 presents descriptive aspects of the indicators used in the taxometric analysis of the present study. All indicators were standardized so that their means are 0 and their standard deviations are 1 . The coefficients $d$ indicate, in each analysis, how much each indicator was able to discriminate between the different individuals of the sample (more precisely, between the possible taxon group and the other individuals). It is a measure of the quality of the indicators, to be inspected before the taxometric analysis. Indicators with a $d \geq 1.25$ are suitable (Meehl, 1995). This condition was satisfied in all cases of the present study, thus supporting the pertinence of the indicators chosen for the taxometric analysis.

Table 1

Descriptive Aspects of Indicators

\begin{tabular}{|c|c|c|c|c|c|}
\hline \multirow[b]{2}{*}{ Subscales } & \multirow[b]{2}{*}{ Asymmetry } & \multirow[b]{2}{*}{ Kurtosis } & \multicolumn{3}{|l|}{ Validity $(d)$} \\
\hline & & & MAMBAC & MAXEIG & Lmode \\
\hline \multicolumn{6}{|l|}{ Antisocial PD } \\
\hline Aggressiveness & 1.28 & 1.83 & 2.14 & 2.67 & 1.60 \\
\hline Grandiosity & 0.67 & -0.05 & 1.66 & 1.72 & 1.55 \\
\hline Impulsivity & 0.85 & 0.06 & 1.82 & 2.07 & 1.61 \\
\hline \multicolumn{6}{|l|}{ Borderline PD } \\
\hline Dependency & 0.51 & -0.22 & 1.41 & 1.43 & 1.42 \\
\hline Instability & 0.07 & -0.81 & 2.08 & 2.08 & 2.09 \\
\hline Impulsivity & 0.85 & 0.06 & 1.28 & 1.30 & 1.33 \\
\hline
\end{tabular}

Taxonomic analysis was then conducted using the MAMBAC, MAXEIG and Lmode methods. The results are described in Table 2, while Figure 1 and Figure 2 show the curves for the APD and BPD indicators, respectively. Each figure shows the curve with the sample data plotted against the two hypothetical curves constructed with simulated data. An evidence of categorical structure occurs when the empirical curve (dotted curve) reveals itself closer to the categorical simulated curve (gray curve with linear contours representing the confidence intervals); an evidence of dimensional structure happens when there are fewer residues between the empirical curve and the dimensional simulated 
curve, that is, when the dotted curve has a shape that is more similar to that of the gray curve in the dimensional condition than in the categorical condition.

In general, considering the CCFI means (Ruscio et al., 2010) and the graphs of Figure 1 and Figure 2, the results revealed clear evidence of dimensionality for APD, but an ambiguous result for BPD. Although we verified a trend towards dimensionality $(0.401$ is closer to 0 than 1$)$, ambiguity in this case does not allow a conclusion as to which type of structure (dimensional or categorical) is the most plausible explanation for the data regarding the BPD.

Table 2

Results of the Taxometric Analysis

\begin{tabular}{lcccc}
\hline \multirow{3}{*}{ Disorders } & \multicolumn{3}{c}{ CCFI by method } & \\
\cline { 2 - 4 } & MAMBAC & MAXEIG & Lmode & CCFI \\
\hline Antisocial PD & 0.194 & 0.407 & 0.226 & 0.276 \\
Borderline PD & 0.395 & 0.581 & 0.241 & 0.401 \\
\hline
\end{tabular}
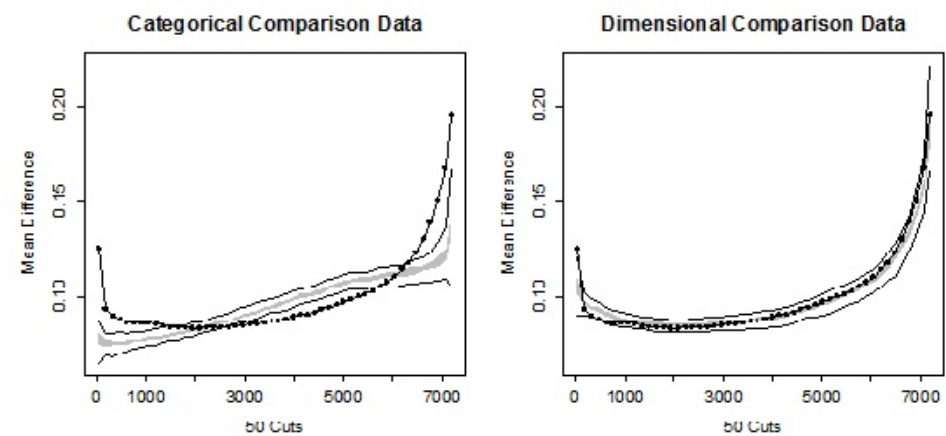

A. MAMBAC
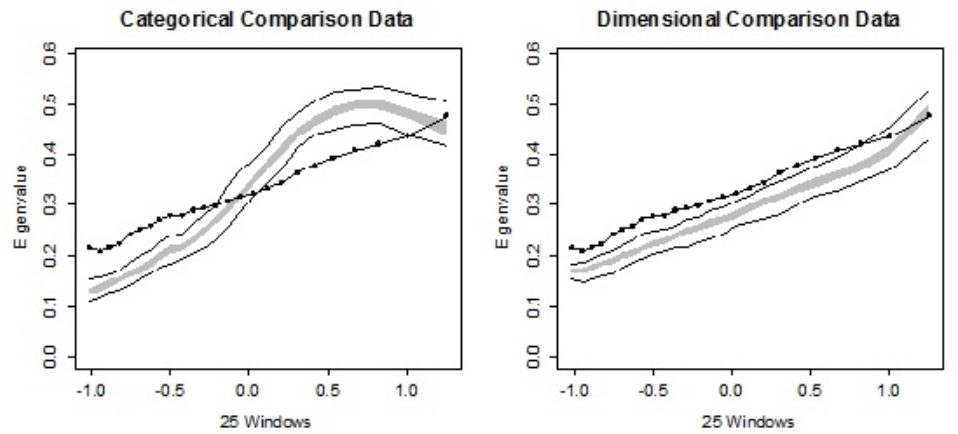

B. MAXEIG
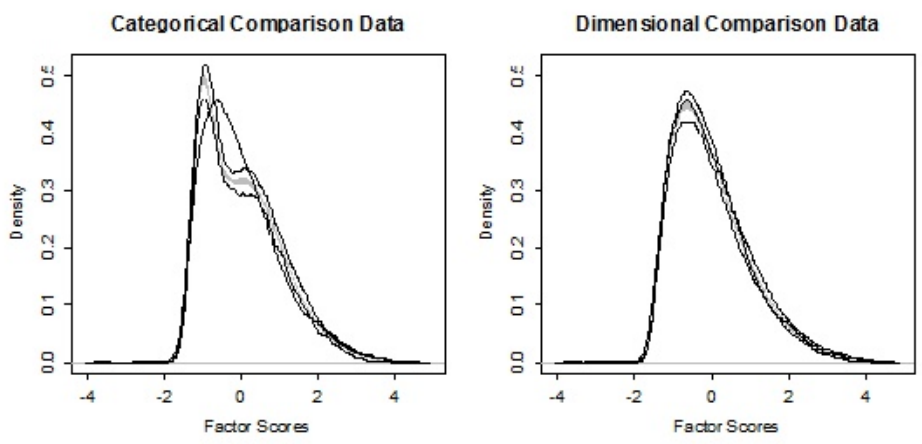

C. Lmode

Figure 1. Taxometric analysis of Antisocial PD indicators. The empirical curve (dotted line) is clearly more similar to the simulated curve (in gray, with linear contours) in the dimensional condition than in the categorical/taxonomic condition. 

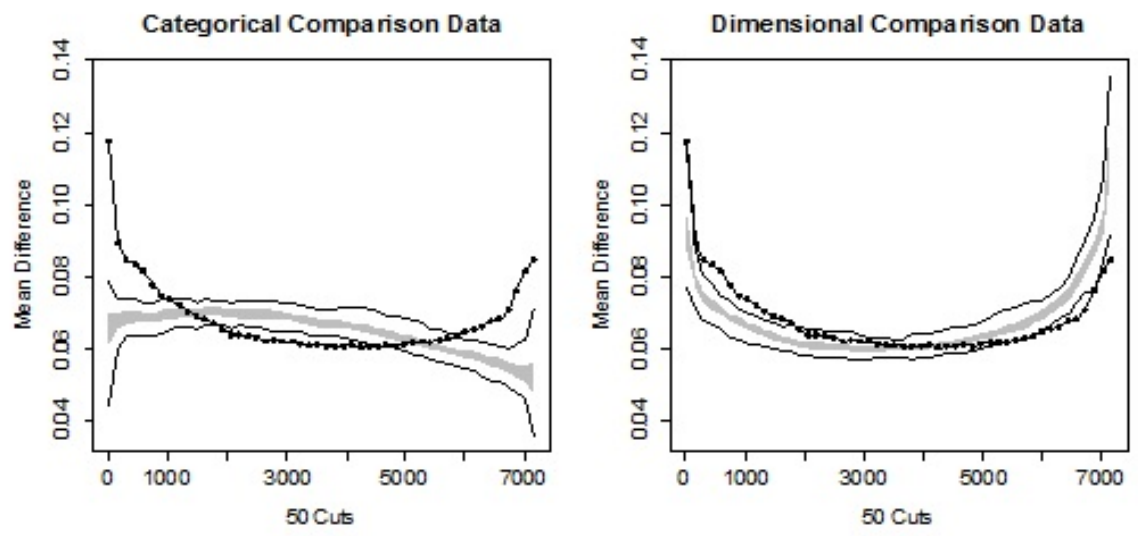

A. MAMBAC
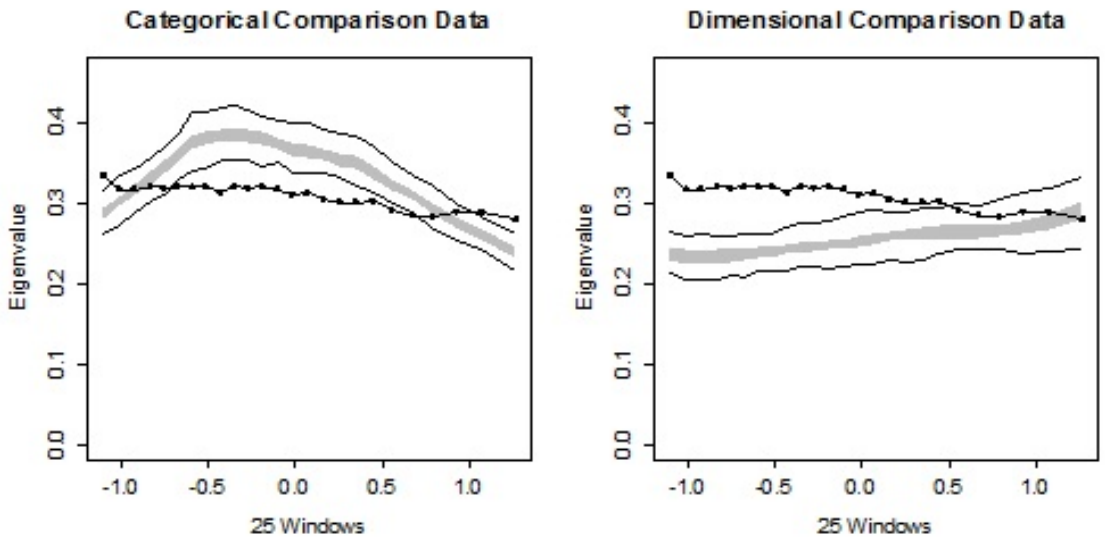

B. MAXEIG
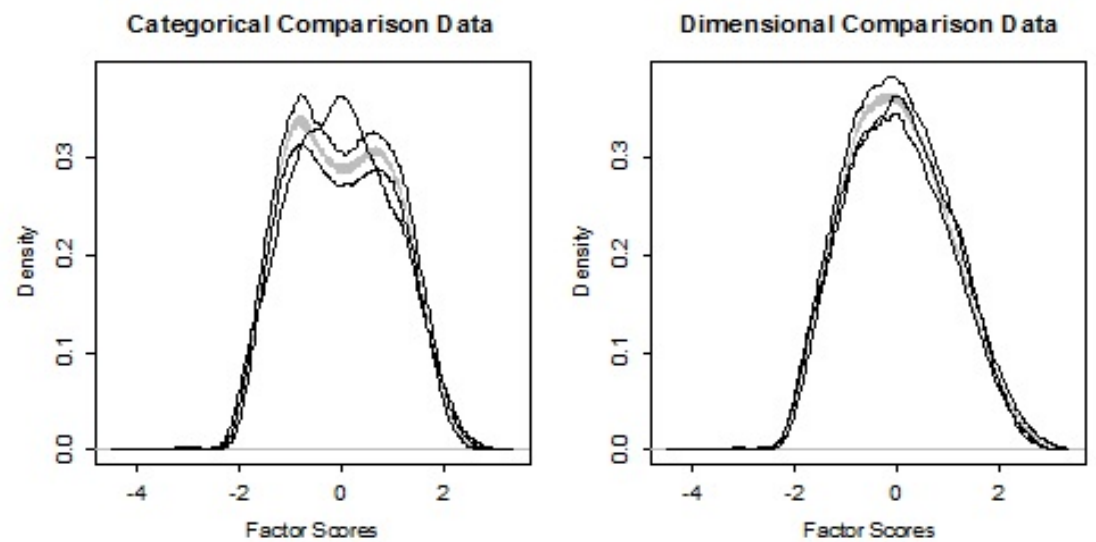

\section{Lmode}

Figure 2. Taxometric analysis of Borderline PD indicators. Only in the Lmode method the empirical curve (dotted line) is more similar to the simulated curve (in gray, with linear contours) in the dimensional condition than in the categorical/taxonomic condition. In other cases, the results are ambiguous. 


\section{Discussion}

The present study presents two main results. First, for APD, taxometric analysis revealed a clear dimensional structure (mean CCFI $=0.276$ ), such as observed in most of the previous studies (Hallquist \& Pilkonis, 2012; Kerridge et al., 2014; Marcus et al., 2006; Ruscio et al., 2010; Walters, 2008, 2011, 2015; Walters et al., 2007), for exceptions see Haslam (2003) and Vasey et al. (2005). This result suggests that there is no natural separation between individuals with and without APD; rather, it seems more plausible the existence of a continuum of antisocial personality along which all individuals of the population are disposed. This is consistent with current empirical models on the basis of antisocial behavior (Walters, 2008, 2009, 2015).

A dimensional approach to APD has clinical and psychometric implications. From a clinical point of view, if APD is continuous, then the classification of individuals into only two discrete groups can lead to a loss of information. For a review on the problems of dichotomization of continuous variables, see MacCallum, Zhang, Preacher and Rucker (2002). Different levels of losses and subtleties of psychological functioning are, in this case, reduced to only two possibilities: those who supposedly have APD, and those who do not. A dimensional evaluation, in contrast, takes into account different degrees of impairment, even among the clinical population. From a psychometric point of view, if APD is of a continuous nature, then every search for an ideal cutoff point is doomed to failure. In this situation, APD indicators, on the other hand, should provide information on the different levels of the continuous latent dimensional variable (Borsboom, 2008)Fourth Edition (DSM-IV; American Psychiatric Association, 1994. Therefore, it may be more relevant to use dimensional tools in the assessment of APD, such as the IDCP (currently used) and other current tools for assessing pathological personality traits (Crego, Samuel, \& Widiger, 2015; Krueger et al., 2012; Miller et al., 2016).

Secondly, for BPD, the results $($ CCFImean $=0.401$ ) are ambiguous (Ruscio et al., 2010), not allowing a conclusion on which type of structure is more plausible, either dimensional or categorical. Part of the literature in the area confirms the observed uncertainty (Arntz et al., 2009; Ruscio et al.,2010), and there are contradictory findings (Hallquist \& Pilkonis, 2012; Haslam, 2003; Lönnqvist et al., 2012; Trull et al., 1990; Vasey et al., 2005). However, some researchers suggest that BPD is a female phenotypic expression of psychopathic traits (Sprague et al., 2012). Considering that most taxometric investigations suggested a dimensional nature of psychopathy (Walters, Ermer, Knight, \& Kiehl, 2015), similar results would be expected for BPD, which did not happen in the present study. Nevertheless, given the ambiguity in the findings, it would be hasty to derive conclusions on whether or not there is a structural differentiation between APD and BPD.

Two alternative hypotheses could explain this specific result for BPD. The first is that, in fact, the disorder does not have a completely dimensional structure, differing from APD. Masyn, Henderson, and Greenbaum (2010) have suggested that in addition to models of latent dimensional and categorical variables, there are other possibilities that fall between these two extremes. For example, it is possible to have a continuum of psychopathology (factor), but with discrete groups (latent classes), each with its own distribution in the variable. In this case, there would be both quantitative differences between individuals - a factor of borderline aspects -, as well as qualitative differences - latent groups or classes of individuals. Future studies could test this hypothesis through factorial models of population mixtures (Lubke \& Muthén, 2005; Masyn et al., 2010), a perspective that represents a new area of research on personality disorders (Wright \& Hallquist, 2014). The other explanation is that the design of the present study produced ambiguous results due to the use of self-report indicators only. In this case, perhaps a multi-method approach, combining indicators from several sources, self-report, hetero-report and biological markers (Walters et al., 2015), would allow a more complete conclusion on the subject.

Overall, the results of the present study clearly point to a dimensional structure of the APD (mean CCFI $=0.276$ ), pointing to the same direction in the case of BPD, even if not evidently $(\mathrm{CCFI}=0.401)$. The findings, therefore, are consistent with a dimensional perspective of personality disorders, contrary to the traditional categorical approach adopted by DSM-5. It is necessary to explain that the mean CCFI value for the BPD resulted only slightly above the range of values recommended by Ruscio et al. (2010) as indicative of a dimensional structure. However, the evidence seems to refute the hypothesis that APD and BPD present a latent categorical structure, as supported by the classic nosographic model officially adopted by the DSM. The study, therefore, adds to the set of findings that suggest that dimensional models are more representative of the nature of personality disorders (Trull, 2005; Trull \& Durrett, 2005; Widiger, 2011; Widiger \& Trull, 2007).

Future studies may focus more closely on the BPD in order to investigate which phenomena, among a number of hypotheses (multidimensionality, mixtures of populations, type of indicator used), contributed to the "marginally" dimensional results found. The exclusive use of self-report indicators in taxonomic analysis is the main limitation of this study to be addressed by new studies, and it is also important that other response scales (for example, dichotomous) be used in taxonomic studies. Other limitations include discrepancies in the characteristics of the clinical and non-clinical samples studied, especially regarding age and education.

\section{References}

American Psychiatric Association. (2013). Diagnostic and Statistical Manual of Mental Disorders: DSM-5(5th ed.).Washington, DC: American Psychiatric Publishing. 
Arntz, A., Bernstein, D., Gielen, D., van Nieuwenhuyzen, M., Penders, K., Haslam, N., \& Ruscio, J. (2009). Taxometric evidence for the dimensional structure of cluster-C, paranoid, and borderline personality disorders. Journal of Personality Disorders, 23(6), 606-628. doi:10.1521/pedi.2009.23.6.606

Beauchaine, T. P., Klein, D. N., Crowell, S. E., Derbidge, C., \& Gatzke-Kopp, L. (2009). Multi finality in the development of personality disorders: A Biology $x$ Sex x Environment interaction model of antisocial and borderline traits. Development and Psychopathology, 21(3), 735-770. doi:10.1017/S0954579409000418

Borsboom, D. (2008). Psychometric perspectives on diagnostic systems. Journal of Clinical Psychology, 64(9), 1089-1108. doi:10.1002/jclp.20503

Carvalho, L. F.,\& Primi, R. (2015). Development and internal structure investigation of the Dimensional Clinical Personality Inventory (IDCP). Psicologia: Reflexão $e$ Crítica, 28(2), 322-330. doi:10.1590/1678-7153.201528212

Carvalho, L. F., \& Primi, R. (2016). Prototype matching of personality disorders with the Dimensional Clinical Personality Inventory. Psicologia: Teoria e Pesquisa, 32(2), e322214. doi:10.1590/0102-3772e322214

Carvalho, L. F., Primi, R., \& Stone, G. E. (2014). Psychometric properties of the Inventário Dimensional Clínico da Personalidade (IDCP) using the Rating Scale Model. Avances en Psicología Latinoamericana, 32(3), 433-446. doi:10.12804/apl32.03.2014.09

Charlise, J. (2014). Using mentalizing and psychopathy to explore a dimensional model of antisocial and borderline personality disorder (Doctoral dissertation). Retrieved from http://discovery.ucl.ac.uk/1448713/1/1055165 Carlisle Josephine Thesis redacted thesis.pdf

Crego, C., Samuel, D. B., \& Widiger, T. A. (2015). The FFOCI and other measures and models of OCPD. Assessment, 22(2), 135-151. doi:10.1177/1073191114539382

Hallquist, M. N., \& Pilkonis, P. A. (2012). Refining the phenotype of borderline personality disorder: Diagnostic criteria and beyond. Personality Disorders, 3(3), 228-246. doi:10.1037/a0027953

Haslam, N. (2003). The dimensional view of personality disorders: A review of the taxometric evidence. Clinical Psychology Review, 23(1), 75-93. doi:10.1016/S0272-7358(02)00208-8

Huchzermeier, C., Geiger, F., Bruss, E., Godt, N., Köhler, D., Hinrichs, G., \& Aldenhoff, J. B. (2007). The relationship between DSM-IV cluster B personality disorders and psychopathy according to Hare's criteria: Clarification and resolution of previous contradictions. Behavioral Sciences \& the Law, 25(6), 901-911. doi:10.1002/bsl.722

Kerridge, B. T., Saha, T. D., \& Hasin, D. S. (2014). DSMIV antisocial personality disorder and conduct disorder: Evidence for taxonic structures among individuals with and without substance use disorders in the general population. Journal of Studies on Alcohol and Drugs, 75(3), 496-509. doi:10.15288/jsad.2014.75.496

Krueger, R. F., Derringer, J., Markon, K. E., Watson, D., \& Skodol, A. E. (2012). Initial construction of a maladaptive personality trait model and inventory for DSM-5. Psychological Medicine, 42(9), 1879-1890. doi:10.1017/S0033291711002674
Lönnqvist, J.-E., Verkasalo, M., Wichardt, P. C., \& Walkowitz, G. (2012). Personality disorder categories as combinations of dimensions: Translating cooperative behavior in borderline personality disorder into the fivefactor framework. Journal of Personality Disorders, 26(2), 298-304. doi:10.1521/pedi.2012.26.2.298

Lubke, G. H., \& Muthén, B. (2005). Investigating population heterogeneity with factor mixture models. Psychological Methods, 10(1), 21-39. doi:10.1037/1082-989X.10.1.21

MacCallum, R. C., Zhang, S., Preacher, K. J., \& Rucker, D. D. (2002). On the practice of dichotomization of quantitative variables. Psychological Methods, 7(1), 19-40. doi:10.1037/1082-989X.7.1.19

Marcus, D. K., Lilienfeld, S. O., Edens, J. F., \& Poythress, N. G. (2006). Is antisocial personality disorder continuous or categorical? A taxometric analysis. Psychological Medicine, 36(11), 1571-1581. doi:10.1017/S0033291706008245

Masyn, K. E., Henderson, C. E., \& Greenbaum, P. E. (2010). Exploring the latent structures of psychological constructs in social development using the dimensionalcategorical spectrum. Social Development, 19(3), 470-493. doi:10.1111/j.1467-9507.2009.00573.x

Meade, A. W., Michels, L. C., \& Lautenschlager, G. J. (2007). Are Internet and paper-and-pencil personality tests truly comparable? An experimental design measurement invariance study. Organizational Research Methods, 10(2), 322-345. doi:10.1177/1094428106289393

Meehl, P. E. (1992). Factors and taxa, traits and types, differences of degree and differences in kind. Journal of Personality, 60(1), 117-174. doi:10.1111/j.1467-6494.1992.tb00269.x

Meehl, P. E. (1995). Bootstraps taxometrics. Solving the classification problem in psychopathology. The American Psychologist, 50(4), 266-275. doi:10.1037/0003-066X.50.4.266

Meehl, P. E., \& Yonce, L. J. (1994). Taxometric analysis: I. Detecting taxonicity with two quantitative indicators using means above and below a sliding cut (MAMBAC procedure). Psychological Reports, 74(3, Pt 2), 1059-1274.

Meehl, P. E., \& Yonce, L. J. (1996). Taxometric analysis: II. Detecting taxonicity using covariance of two quantitative indicators in successive intervals of a third indicator (MAXCOV procedure). Psychological Reports, $78(3$ Suppl.), 1091-1227. doi:10.2466/pr0.1996.78.3c.1091

Miller, J. D., Lynam, D. R., McCain, J. L., Few, L. R., Crego, C., Widiger, T. A., \& Campbell, W. K. (2016). Thinking structurally about narcissism: An examination of the five-factor narcissism inventory and its components. Journal of Personality Disorders, 30(1), 1-18. doi:10.1521/pedi_2015_29_177

Naglieri, J. A., Drasgow, F., Schmit, M., Handler, L., Prifitera, A., Margolis, A., \& Velasquez, R. (2004). Psychological testing on the Internet: New problems, old issues. The American Psychologist, 59(3), 150-162. doi:10.1037/0003-066X.59.3.150

Noyes, J. M., \& Garland, K. J. (2008). Computer-vs. paperbased tasks: Are they equivalent? Ergonomics, 51(9), 1352-1375. doi:10.1080/00140130802170387 
Paris, J. (1997). Antisocial and borderline personality disorders: Two separate diagnoses or two aspects of the same psychopathology? Comprehensive Psychiatry, 38(4), 237-242. doi:10.1016/S0010-440X(97)90032-8

Peluso, M. A. M., \& Andrade, L. H. S. G. (2011). Transtornos de personalidade: Epidemiologia [Personality disorders: Epidemiology]. In M. R.Louzã Neto \& T. A. Cordás, Transtornos de personalidade (pp. 25-38). Porto Alegre, RS: Artmed.

Pinto, A. M. F. (2006). Sobre a dificuldade de exercer a função analítica em paciente borderline [About the difficulty of exercising the analytic function in borderline patient]. Psicanalitica, 7(1), 103-118.

Romaro, R. A. (2002). O sentimento de exclusão social em personalidade borderline e o manejo da contratransferência [Feeling of exclusion in borderline patients and the counter transference management]. Mudanças, 10(1), 65-71.

Ross, S. R., Keiser, H. N., Strong, J. V., \& Webb, C. M. (2013). Reinforcement sensitivity theory and symptoms of personality disorder: Specificity of the BIS in Cluster C and BAS in Cluster B. Personality and Individual Differences, 54(2), 289-293. doi:10.1016/j.paid.2012.09.020

Ruscio, J., \& Marcus, D. K. (2007). Detecting small taxa using simulated comparison data: A reanalysis of Beach, Amir, and Bau's (2005) data. Psychological Assessment, 19(2), 241-246. doi:10.1037/1040-3590.19.2.241

Ruscio, J., Ruscio, A. M., \& Meron, M. (2007). Applying the bootstrap to taxometric analysis: Generating empirical sampling distributions to help interpret results. Multivariate Behavioral Research, 42(2), 349-386. doi:10.1080/00273170701360795

Ruscio, J., Walters, G. D., Marcus, D. K., \& Kaczetow, W. (2010). Comparing the relative fit of categorical and dimensional latent variable models using consistency tests. Psychological Assessment, 22(1), 5-21. doi:10.1037/a0018259

Sadi, H. M. (2011). Análise dos comportamentos de terapeuta e cliente em um caso de transtorno de personalidade borderline [Analysis of therapists and patients behavior in a case of borderline personality disorder] (Doctoral dissertation). Retrieved from http://www.teses.usp.br/ teses/disponiveis/47/47133/tde-04112011-115705/en.php

Samuel, D. B., \& Widiger, T. A. (2008). A meta-analytic review of the relationships between the five-factor model and DSM-IV-TR personality disorders: A facet level analysis. Clinical Psychology Review, 28(8), 1326-1342. doi:10.1016/j.cpr.2008.07.002

Shedler, J., Beck, A., Fonagy, P., Gabbard, G. O., Gunderson, J., Kernberg, O., ... Westen, D. (2010). Personality disorders in DSM 5. American Journal of Psychiatry, 167(9), 1026-1028. doi:10.1176/appi.ajp.2010.10050746

Skodol, A. E., Clark, L. A., Bender, D. S., Krueger, R. F., Morey, L. C., Verheul, R., ...Oldham, J. M. (2011). Proposed changes in personality and personality disorder assessment and diagnosis for DSM-5 Part I: Description and rationale. Personality Disorders: Theory, Research, and Treatment, 2(1), 4-22. doi:10.1037/a0021891
Sousa, A. C. A. (2003). Transtorno de personalidade borderline sob uma perspectiva analítico-funcional [Borderline personality disorder under a functional analytic perspective]. Revista Brasileira de Terapia Comportamental e Cognitiva, 5(2), 121-137. Retrieved from http://pepsic.bvsalud.org/pdf/rbtcc/v5n2/v5n2a04.pdf

Sprague, J., Javdani, S., Sadeh, N., Newman, J. P., \& Verona, E. (2012). Borderline personality disorder as a female phenotypic expression of psychopathy? Personality Disorders, 3(2), 127-139. doi:10.1037/a0024134

Tanesi, P. H. V., Yazigi, L., Fiore, M. L. M., \& Pitta, J. C. N. (2007). Adesão ao tratamento clínico no transtorno de personalidade borderline [Compliance in the treatment of borderline personality disorders]. Estudos de Psicologia (Natal), 12(1), 71-78. doi:10.1590/S1413-294X2007000100009

Trull, T. J.(2005). Dimensional models of personality disorder: Coverage and cutoffs. Journal of Personality Disorders, 19(3), 262-282. doi:10.1521/pedi.2005.19.3.262

Trull, T. J., \& Durrett, C. A. (2005). Categorical and dimensional models of personality disorder. Annual Review of Clinical Psychology, 1, 355-380. doi:10.1146/ annurev.clinpsy.1.102803.144009

Trull, T. J., Tragesser, S. L., Solhan, M., \& Schwartz-Mette, R. (2007). Dimensional models of personality disorder: Diagnostic and Statistical Manual of Mental Disorders Fifth Edition and beyond. Current Opinion in Psychiatry, 20(1), 52-56.doi:10.1097/YCO.0b013e328010c838

Trull, T. J., Widiger, T. A., \& Guthrie, P. (1990). Categorical versus dimensional status of borderline personality disorder. Journal of Abnormal Psychology, 99(1), 40-48. doi:10.1037/0021-843X.99.1.40

Vasey, M.W., Kotov, R., Frick, P.J., \& Loney, B. R. (2005). The latent structure of psychopathy in youth: A taxometric investigation. Journal of Abnormal Child Psychology, 33(4), 411-429. doi:10.1007/s10802-005-5723-1

Völlm, B., Richardson, P., Stirling, J., Elliott, R., Dolan, M., Chaudhry, I., ... Deakin, B. (2004). Neurobiological substrates of antisocial and borderline personality disorder: Preliminary results of a functional fMRI study. Criminal Behaviour and Mental Health, 14(1), 39-54. doi:10.1002/cbm.559

Waller, N. G., \& Meehl, P. E. (1998). Multivariate taxometric procedures: Distinguishing types from continua. Thousand Oaks, CA: Sage.

Walters, G. D. (2008). Self-report measures of psychopathy, antisocial personality, and criminal lifestyle: Testing and validating a two-dimensional model. Criminal Justice and Behavior, 35(12), 1459-1483. doi:10.1177/0093854808320922

Walters, G. D. (2009). Latent structure of a twodimensional model of antisocial personality disorder: Construct validation and taxometric analysis. Journal of Personality Disorders, 23(6), 647-660. doi:10.1521/pedi.2009.23.6.647

Walters, G. D. (2011). The latent structure of lifecourse-persistent antisocial behavior: Is Moffitt's developmental taxonomy a true taxonomy? Journal of Consulting and Clinical Psychology, 79(1), 96-105. doi:10.1037/a0021519 
Walters, G. D. (2012). Taxometrics and criminal justice: Assessing the latent structure of crime-related constructs. Journal of Criminal Justice, 40(1), 10-20. doi:10.1016/j.jcrimjus.2011.11.003

Walters,G.D.(2015).Atwo-dimensionalmodelofpsychopathy and antisocial behavior: A multi-sample investigation using items from the Psychopathy Checklist-Revised. Personality and Individual Differences, 78, 88-93. doi:10.1016/j.paid.2015.01.037

Walters, G. D., Diamond, P. M., Magaletta, P. R., Geyer, M. D., \& Duncan, S. A. (2007). Taxometric analysis of the antisocial features scale of the personality assessment inventory in federal prison inmates. Assessment, 14(4), 351-360. doi:10.1177/1073191107304353

Walters, G. D., Ermer, E., Knight, R. A., \& Kiehl, K. A. (2015). Paralimbic biomarkers in taxometric analyses of psychopathy: Does changing the indicators change the conclusion? Personality Disorders: Theory, Research, and Treatment, 6(1), 41-52. doi:10.1037/per0000097

Widiger, T. A. (2011). A shaky future for personality disorders. Personality Disorders: Theory, Research, and Treatment, 2(1), 54-67. doi:10.1037/a0021855

Widiger, T. A.,\& Trull, T. J. (2007). Plate tectonics in the classification of personality disorder: Shifting to a dimensional model. American Psychologist, 62(2), 71-83. doi:10.1037/0003-066X.62.2.71

Wright, A. G. C., \& Hallquist, M. N. (2014). Introduction to the special section on mixture modeling in personality assessment. Journal of Personality Assessment, 96(3), 253-255. doi:10.1080/00223891.2013.866572

Zanin, C. R., \& Valerio, N. I. (2004). Intervenção cognitivocomportamental em transtorno de personalidade dependente: Relato de caso [Cognitive behavior therapy for dependent personality disorder: A case report]. Revista Brasileira de Terapia Comportamental $e$ Cognitiva, 6(1), 81-92. Retrieved from http://pepsic.bvsalud.org/pdf/rbtcc/v6n1/v6n1a09.pdf

Zimmerman, M. (2012). Is there adequate empirical justification for radically revising the personality disorders section for DSM 5? Personality Disorders: Theory, Research, and Treatment, 3(4), 444-457. doi:10.1037/a0022108

Lucas de Francisco Carvalho is a Professor of the Stricto Sensu Graduate Program in Psychology at the Universidade São Francisco, Campinas-SP, Brazil.

Nelson Hauck Filho is a Professor of the Stricto Sensu Graduate Program in Psychology at the Universidade São Francisco, Campinas-SP, Brazil.

Giselle Pianowski is a postdoctoral student of the Stricto Sensu Graduate Program in Psychology at the Universidade São Francisco, Campinas-SP, Brazil.

Luana Comito Muner is a Professor of the Faculdade Cathedral, Boa Vista-RR, Brazil.
Authors' Contribution:

All authors made substantial contributions to the conception and design of this study, to data analysis and interpretation, and to the manuscript revision and approval of the final version. All the authors assume public responsability for content of the manuscript.

Received: May. 03, 2016

1st Revision: Aug. 03, 2016

2nd Revision: Oct. 26, 2016

Approved: Jan. 30, 2017

How to cite this article:

Carvalho, L. F., Hauck Filho, N., Pianowski, G., \& Muner, L. C. (2019). Latent structure of antisocial and borderline personality disorders: A taxometric research. Paidéia (Ribeirão Preto), 29, e2902. doi: http://dx.doi.org/10.1590/1982-4327e2902 